\title{
RESEARCH
}

\section{Longitudinal Measurement of Empathy in Student Pharmacists}

\author{
Paul C. Walker, PharmD, Vincent D. Marshall, MS, Burgunda V. Sweet, PharmD, Sarah E. Vordenberg, \\ PharmD, MPH
}

The University of Michigan, College of Pharmacy, Ann Arbor, Michigan

Corresponding Author: Paul C. Walker, The University of Michigan, College of Pharmacy, 428 Church St., Ann Arbor, MI 48109 1065. Tel: 734-763-0091. Email: pcwalker@umich.edu

Submitted May 26, 2021; accepted October 27, 2021; ePublished November 2021

Objective. To assess empathy longitudinally in student pharmacists and describe how it changes during their four years of pharmacy education.

Methods. The Jefferson Scale of Empathy Health Professions Student version (JSE-HPS) was completed by a cohort of student pharmacists at the beginning and end of PY1 year, then at the end of PY2, PY3, and P4 years. Demographic data and information about students' previous pharmacy work experience and experience interacting with patients were also collected.

Results. Student pharmacists' empathy scores were relatively high at the beginning of PY1 year, comparable to scores reported for medical and other health professions students. Empathy scores declined over the first two years of the pharmacy curriculum but increased during both PY3 and P4 year, recovering to the level observed at the beginning of PY1 year. Factor analysis identified three factors, "perspective-taking," "compassionate care," and "walking in patient's shoes" which accounted for $26 \%, 19 \%$ and $7 \%$ of the variance, respectively, and supported the construct validity of the JSE-HPS.

Conclusion. Student pharmacist empathy decreased during the early primarily didactic years of the pharmacy curriculum but increased during the latter years that emphasize clinical experiences.

Keywords: assessment, empathy, pharmacy, student pharmacists

\section{INTRODUCTION}

Empathy is integral to the therapeutic relationship between health care providers and patients. Empathic engagement with patients leads to more accurate diagnoses; improved adherence with health care recommendations and clinical outcomes; reduced patient anxiety, depression, and hostility; and increased patient satisfaction with their care ${ }^{1-9}$ It is an important skill pharmacists must have as they increasingly engage in therapeutic relationships with patients. ${ }^{10}$ However, there is no consensus definition, which complicates the teaching and measurement of empathy. The Jefferson Scale of Empathy (JSE), specifically designed for health care education, is based on the definition of empathy as, "A predominantly cognitive (as opposed to an affective) attribute that involves understanding (rather than feeling) of a patient's concerns, experiences, pain, and suffering combined with a capacity to communicate this understanding and an intention to help". ${ }^{12,13}$ Versions of the JSE are available for use with medical students (JSE-S) and students of other health care disciplines (JSE-HPS), including student pharmacists. ${ }^{14,15}$

The JSE is the most well-studied and widely used instrument for assessing empathy in medical education. ${ }^{16-18}$ It has been used to establish normative data and cutoff JSE-S scores for U.S. medical students which may be useful in identifying high- and low-scoring students and students who may need to improve their empathy skills. ${ }^{19-20}$ Studies using versions of the JSE to describe empathy development in students matriculating through medical school and other health professions schools report relatively high empathy scores in medical, nursing and dental learners early in their professional education, with scores declining significantly over time, especially during the clinical learning experiences in the final years of training. ${ }^{21-33}$ Empathy development in student pharmacists may follow a similar pattern; however, specific longitudinal evidence is lacking. The available evidence consists of cross-sectional studies that assess empathy across cohorts of student pharmacists by year of study or that evaluate changes in empathy following single, short-term empathy-enhancing interventions. ${ }^{21,34-36}$ Measuring empathy as an educational outcome and understanding how it changes over the course of the curriculum may inform curricular changes to help students enhance their empathy skills. We describe using the JSP-HPS in a single cohort of student pharmacists during their four years of pharmacy education. The study objectives were to examine evidence of instrument validity when used in student pharmacists and to identify 
whether patterns of empathy scores evolved over time in a pattern similar to that seen in other health care provider students.

\section{METHODS}

Our Doctor of Pharmacy program is a 4-year curriculum. The first 3 years of the curriculum are primarily didactic; the last year is experiential. Empathy is taught as a communication skill in the first semester of pharmacy year 1 (PY1). Students also engage in standardized patient (SP) interactions throughout the first 3 years of the curriculum: 16 interactions in PY1, 5 in pharmacy year 2 (PY2), and 5 in pharmacy year 3 (PY3). Students also practice empathy during introductory pharmacy practice experiences (IPPEs) in the community and health-system settings during PY2 and PY3, respectively. In IPPEs, empathy is assessed as a component of professional and ethical behavior, not as a separate criterion.

The JSE-HPS is a 20-item questionnaire that assesses cognitive empathy. Scores range from 20 to 140; higher scores indicate a more empathic orientation. The JSE-HPS was administered to a single cohort of student pharmacists (class of 2019) during their enrollment in the Doctor of Pharmacy program. Students were invited to complete the JSEHPS questionnaire as an online survey (Qualtrics, Provo, Utah, USA) at the beginning of PY1 (baseline) and at the end of PY1 after their introduction to the concept of empathy in the didactic curriculum but before completing any IPPEs. The JSE-HPS was then completed at the end of the PY2, PY3, and the fourth year (PY4) of the curriculum. A link to the survey was emailed to students. During PY1, PY2 and PY3, students completed the survey as a self-assessment during a class session; however, they were given the option to opt out of having their data used for research purposes. The JSEHPS was administered during PY4 as part of the end-of-year exit surveys. Gender, age, and information about students' previous pharmacy work experience and experience interacting with patients were collected. Survey data were deidentified prior to analysis to protect confidentiality. The study that was granted exempt status by the Institutional Review Board.

Student baseline characteristics of gender, age group in years, prior work in a pharmacy, and prior contact with patients were summarized with counts and percentages. Empathy scores were generated by scoring the JSE-HPS using the algorithm provided by Thomas Jefferson University. JSE-HPS mean scores for groups within each baseline characteristic were compared using a one-way ANOVA if there were three or more groups, and a t-test for independent samples if there were two groups. Mean JSE-HPS scores at each data collection point (start of PY1, and ends of PY1, PY2, PY3, and PY4) were also compared using ANOVA. Data distributions for each group were summarized by using the measures of means, medians, skewness, and kurtosis.

To validate the internal structure of the JSE-HPS, an exploratory factor analysis was performed. The Kaiser criterion, specifying that only factors with an eigenvalue of $>1$ should be included, was used to determine the number of factors. To determine whether the data were fit for a factor analysis, Bartlett's test of sphericity and the Kaiser-MeyerOlkin (KMO) statistic were performed; Kaiser's categorization of the KMO statistic was also considered. ${ }^{37,38}$ After determining an appropriate factor analysis model, we ascertained its model goodness of fit with a confirmatory factor analysis. The reliability, a measure of construct validity of the model, was examined using the Algebraic Greatest Lower Bound (GLB) method. The GLB was used instead of Cronbach's alpha because of the multidimensional aspect of the JSE scores, and instead of coefficient omega because of the skewness in the JSE component variable distributions. To evaluate changes in students' empathy scores year-by-year, we used a linear mixed model with random intercepts for each participant's data. Adding the random intercepts allowed for estimating the correlation between a person's repeated observations. Tukey's honest significant difference (HSD) was used to correct for multiple comparisons.

All analyses were performed with R (version 4.0.4), using the REdaS package for the Bartlett's sphericity and KMO statistics, the RCSDP package for the algebraic greatest lower bound and the lavaan package for the confirmatory factor analysis. ${ }^{39-42}$

\section{RESULTS}

All 85 PY1 students of the class of 2019 were invited to participate; the JSE-HPS was completed by $82(96.4 \%)$ students at the beginning of PY1. Student demographic characteristics at baseline (beginning of PY1) are shown in Table 1. Most students were female; students who did not specify their gender were excluded from all gender comparisons but were otherwise included in the analyses. Most students $(62.2 \%)$ were 22 to 24 years of age and had pharmacy work experience or experience interacting with patients prior to entering pharmacy school.

The number of students who completed the JSE-HPS at the ends of PY1, PY2 PY3, and PY4 are shown in Table 2. The mean empathy score (SD) at baseline was 111.5 (10.5); empathy scores were higher for male students compared to 
female students, although the difference was not statistically significant (Table 1). There was no significant effect of age, previous pharmacy experience, or previous experience interacting with patients on baseline empathy scores.

Summary statistics of the empathy score distributions by year and gender are shown in Table 2. JSE-HPS score distributions for the cohort were negatively skewed, but the effect on the distributions was not significant. Skewness measures the asymmetry of a probability distribution. The skewness for a normal distribution is 0 . A positive skewness corresponds to a long tail to the right with the peak of the score distribution tending to occur on the left of the distribution; a negative skewness corresponds to a long tail to the left with the peak of the score distribution tending to occur on the right of the distribution. A distribution is approximately symmetric if skewness is between -.5 and .5 . Analysis of the distributions showed that the skewness of the overall and yearly data was negative.

Kurtosis, which is related to the tails of the distribution relative to that of the normal distribution is a measure of the outliers present in a distribution. The normal (Gaussian) distribution has a kurtosis of 3 . Values less than 3 correspond to a distribution having fewer outliers and values greater than 3 correspond to a distribution with more outliers. ${ }^{43}$ Values between -2 and +2 are considered acceptable to prove normal distribution of the data. ${ }^{33}$ The kurtosis of 3.03 in the overall set reveals the data to be mesokurtic; distributions of individual years had kurtosis values greater or less than three. The Algebraic Greatest Lower Bound reliability scores were all greater than .90, indicating a good level of internal consistency within and across the years of the study.

Over the first two years of the pharmacy curriculum, mean empathy scores declined (Table 3). No significant differences were found between scores at baseline and the end of PY1 or between scores at the end of PY1 and the end of PY2. However, the difference in scores between baseline and the end of PY2 were statistically significant $(\mathrm{p}=.034)$. Scores at the end of PY3 were higher than scores at the end of PY1, although the difference did not reach statistical significance $(p=0.054)$. Scores were significantly higher at the end of PY3 compared to end of PY2 $(p=.003)$ and were significantly higher at the end of PY4 compared to both the end of PY1 $(p=.012)$ and the end of PY2 ( $<.001)$. Scores at the end of PY4 were not significantly different from scores at baseline or the end of PY3.

Three factors with eigenvalues of $>1$, corresponding to those titled "Perspective Taking," "Compassionate Care," and "Walking in Patient's Shoes" were identified. ${ }^{13}$ The eigenvalue of these three factors were 4.42, 3.17, and 1.14. These three factors accounted for $26 \%, 19 \%$, and $7 \%$ of the total variance, respectively, which explains $52 \%$ of all variation in the data. The GLB for these factors was $.92, .86$, and 0.70 , respectively, suggesting adequate reliability of the components within the factors. In the overall factor analysis, there was no problem with items belonging to multiple factors. Both Bartlett's test $\left(\chi^{2}(136)=2568, \mathrm{p}<.001\right)$ and the KMO statistic $(.902$, "Marvelous") confirmed that the data were suited to a factor analysis, and a confirmatory factor analysis showed adequate model goodness of fit (model $\chi^{2}=318.99$, $\mathrm{p}<0.001$, Comparative Fit Index 0.935, and the RMSEA 0.058, $\mathrm{p}=0.059$ ). The model showed good reliability with a GLB of .923.

\section{DISCUSSION}

Cognitive empathy development in students matriculating through medical school has been well-described. ${ }^{21-28}$ National normative data and cutoff scores have been reported that may be useful in identifying high- and low-scoring students, developing strategies to support students who may need to improve their empathy skills, and perhaps, under certain circumstances, even be used as part of medical school admission decisions. ${ }^{19}$ Similar data have not been reported for student pharmacists. It is therefore unclear what levels of empathy should be expected at various stages of their professional development as they progress through the pharmacy curriculum or at what level remediation to improve empathy would be helpful.

The relatively high empathy score observed at baseline is similar to scores reported for student pharmacists, medical students, and nursing students enrolled in the first year of their respective professional curricula. ${ }^{17,19,32-36}$ No gender-related difference in baseline empathy scores was observed, and age did not affect baseline empathy scores.

Empathy scores declined over the first two years of the curriculum but increased during the last two years of the curriculum, which is contrary to trends observed in other studies and may be due to when the clinical training occurs in other health professions students' curricula. Empathy scores in other health professions students are generally stable in the early preclinical years of study but tend to decline significantly during the third and fourth clinical years of study. ${ }^{22-34}$ Williams and colleagues observed lower empathy scores in PY2 and PY3 compared to PY1 students, although the differences were not significant and methodological differences may account for the different results. ${ }^{36}$

Why empathy scores declined in our study during PY1 and PY2 is not clear. During these years of our curriculum, students practice empathy skills by interacting with SPs; however, these interactions may lack the genuine connection and tangible impact that real-world interpersonal interactions can provide. Practicing empathy skills in a contrived setting with SPs may fall short in helping students maintain or improve their empathy skills, but may enhance their self-awareness of their empathy skills, resulting in a more critical self-assessment of their skills. Together with 
limited interactions with real patients, the lack of specific, focused feedback on empathy during PY2 IPPEs may contribute to the decline in empathy scores. Additional studies are needed to confirm this observation. Students may also experience stress and academic burnout as they adjust to the rigor of the pharmacy curriculum in PY1 and the challenges of PY2, which is the most arduous year in our PharmD program. The effect of stress and academic burnout on empathy is controversial and it is not clear if stress contributed to the decline in empathy scores. ${ }^{44-46}$

Our PY3 IPPEs provide students with substantial patient interactions and specific feedback on interpersonal communication skills, including empathy. ${ }^{47,48}$ Further, the entire fourth year is devoted exclusively to advanced pharmacy practice experiences (APPEs), many of which are clinically oriented with significant direct patient care responsibilities, opportunities to exercise empathy, and frequent assessment of interpersonal communication. This increased exposure and application of empathy skills in the real-world settings provided by IPPEs and especially APPEs may have contributed to the increased empathy scores observed in PY3 and PY4. This contrasts with observations of declining empathy scores in medical students during the final years of training and may suggest differences between disciplines in how empathy is emphasized, reinforced, or modeled in the curriculum.

Students' individual experiences with preceptors during these clinical experiences likely contributed to the enhanced empathy scores observed at the end of PY3 and PY4. The ability of preceptors to effectively model empathy has been suggested to impact the development of empathy in student pharmacists. ${ }^{36}$ Careful attention to student workload and preceptors' modeling empathic behavior may have mitigated the adverse impacts on empathy reported to occur during the later clinical phase of health professions education. ${ }^{20-32}$ The specific impact of experience with preceptors on empathy was not assessed in this study.

The distribution of JSE-HPS scores, although slightly negatively skewed, did not differ significantly from the normal distribution. These results are similar to findings in medical students who completed the JSE-S. ${ }^{19}$ The three-factor JSE-HPS structure found here corresponds with the structure reported for the JSE in medical students and physicians. ${ }^{13,18}$ The three factors accounted for $52 \%$ of all variation in our data; in comparison, these three factors explained $36 \%$ of the variation in physicians and $45 \%$ in medical students. ${ }^{13,18}$ In contrast, other studies in student pharmacists have reported a two-factor structure for the JSE-HPS. ${ }^{15}{ }^{36}$ Different approaches to factor analyses may account for the differences in factor structure between studies.

The results of this study are limited because it was conducted in a relatively small convenience sample of student pharmacists enrolled in a 4-year Doctor of Pharmacy program at a single university. The small number of student pharmacists who completed the JSE-HPS at the end of PY3 may also limit the interpretation of the results for PY3. During PY1 and PY2, students completed the JSE-HPS as a required course self-reflection but could opt out of having their data included in the study; during PY3, completion of the JSE-HPS was optional, which likely contributed to this low response rate. The mean of all JSE-HPS scores (beginning of PY1 through PY4) submitted by the 20 students who completed the questionnaire in PY3 was significantly higher than the mean of all JSE-HPS scores of the 62 students who did not (116.8 (10.1) vs. 109.0 (13.5), respectively; independent samples t-test, $\mathrm{p}<.001$ ). This suggests that students who submitted the questionnaire in PY3 were high scorers compared to those who did not; thus, the results for PY3 may be biased and should be interpreted with caution.

Longitudinal development or change in student pharmacist empathy has not been previously described. We are not able to draw conclusions about changes in empathy scores over time in pharmacy programs whose students have different demographic characteristics. However, the empathy scores and factor analyses reported here are similar to the

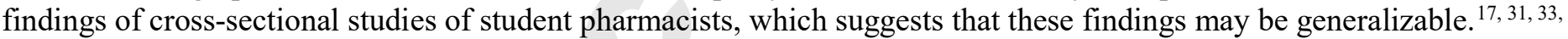

${ }^{35}$ Additional longitudinal studies could validate our results and help to better elucidate how empathy changes over the course of pharmacy education.

Additionally, student pharmacists completed the JSE-HPS 5 times, which may introduce retest bias from multiple exposures to the same survey instrument. While this is difficult to control for, empathy scores, as measured by the JSE, have demonstrated stability over time by test-retest reliability and retest bias is likely not a significant concern. ${ }^{13,49}$

\section{CONCLUSION}

Empathy is a core skill that student pharmacists must develop. This longitudinal study found that empathy decreased during the early, mostly didactic years of the pharmacy curriculum, but increased during the latter years which tend to emphasize clinical experiences. Greater involvement in early direct patient care activities, which already occurs in the latter two years of the curriculum, may improve students' empathy, and prevent the decline. 


\section{REFERENCES}

1. Reiss H. Empathy in medicine: a neurological perspective. JAMA. 2010;304(14):1604-1605.

2. Veloski JJ, Fields SK, Boex JR, Blank LL. Measuring professionalism: A review of studies with instruments reported in the literature between 1982 and 2002. Acad Med. 2005; 80(4):366-70.

3. Veloski J, Hojat M. Measuring specific elements of professionalism: Empathy, teamwork, and lifelong learning. In: DT Stern. Measuring Medical Professionalism. New York, NY: Oxford University Press. 2006.

4. Hojat M, Louis DZ, Markahm FW, et al. Physician empathy and clinical outcomes for diabetic patients. Acad Med. 2011; 86(3):359-364.

5. Del Canale S, Louis DZ, Maio V, et al. Physician empathy and disease complications: an empirical study of primary care physicians and their diabetic patients in Parma, Italy. Acad Med. 2102; 87(9):1243-9.

6. Barski AJ. Hidden reasons some patients visit doctors. Ann Intern. Med. 1981;94:492-498.

7. DiMatteo MR, Sherbourne CD, Hays RD, Ordway L, et al. Physicians' characteristics influence patients' adherence to medical treatment: Results from the medical outcomes study. Health Psychol. 1993; 12(2):93-102.

8. LaMonica E, Wolf RM, Madea A, Oberst M. Empathy and nursing care outcomes. Sch Inq Nurs Pract. 1987; 1(3):197-213.

9. Zacharia R, Pedersen CG, Jensen AB, Ehrnrooth E, Rossen PB, Von der Maase H. Association of perceived physician communication style with patient satisfaction, distress, cancer-related self-efficacy, and perceived control over the disease. Br J Cancer. 2003; 10;88(5):658-65.

10. Accreditation Council for Pharmacy Education. Accreditation Standards and Key Elements for The Professional Program In Pharmacy Leading To The Doctor Of Pharmacy Degree. Released February 2, 2015. https://www.acpeaccredit.org/pdf/Standards2016FINAL.pdf. Accessed May 4, 2021.

11. Ratka A. Empathy and the development of affective skills. Am J Pharm Educ. 2018; 82(10): Article 7192. https://www.ajpe.org/content/82/10/7192.

12. Hojat M. Empathy in Patient Care: Antecedents, Development, Measurement, and Outcomes. New York, NY: Springer; 2007.

13. Hojat M, Gonnella JS, Nasca TJ, et al. Physician empathy: definition, components, measurement, and relationship to gender and specialty. Am J Psychiatry. 2002; 159(9):1563-9.

14. Fields KS, Mahan P, Hojat M, Tillman P, Maxwell K. Measuring empathy in healthcare profession students using the Jefferson Scale of Physician Empathy: health provider-student version. J Interprofessional Care. 2011; 25(4):287-93.

15. Fjortoft N, van Winkle LJ, Hoja M. Measuring empathy in student pharmacists. Am J Pharm Educ. 2011; 75(6): Article 109. https://doi.org/10.5688/ajpe756109.

16. Sulzer SH, Feinstein NW, Wendland CL. Assessing empathy development in medical education: A systematic review. Med Educ. 2016; 50(3):300-10.

17. Colliver JA, Conlee MJ, Verhulst SJ, Dorsey JK. Rebuttals to critics of studies of the decline of empathy. Acad Med. 2010; 85(12):1813.

18. Hojat M, DeSantis J, Shannon SC, Mortensen LH, Speicher MR, Bragan L, LaNoue M, Calabrese LH. The Jefferson Scale of Empathy: a nationwide study of measurement properties, underlying components, latent variable structure, and national norms in medical students. Adv Health Sci Educ Theory Pract. 2018; 23(5):899-920.

19. Hojat M, Gonnella JS. Eleven years of data on the Jefferson Scale of Empathy-Medical Student Version (JSE-S): Proxy norm data and tentative cutoff scores. Med Princ Pract. 2015; 24(4):344-50.

20. Hojat M, Calabrese LH, Shannon SC, DeSantis J, Speicher M, Bragan L. Final Report: Project in Osteopathic Medical Education and Empathy. Empathy in Medicine National Norms for the Jefferson Scale of Empathy: A Nationwide Project in Osteopathic Medical Education and Empathy (POMEE). J Am Osteopath Assoc. 2019 Aug 1;119(8):520-532.

21. Hojat M, Gonnella JS, Nasca TJ, et al. Empathy in medical students as related to academic performance, clinical competence, and gender. Med Educ. 2002; 36(6):522-7.

22. Hojat M, Mangione S, Nasca TJ, Gonnella JS. Empathy scores in medical school and ratings of empathic behavior 3 years later. J Soc Psychol. 2005;145(6):663-672.

23. Chen D, Lew R, Hershman W, Orlander J. A cross-sectional measurement of medical student empathy. Soc Gen Intern Med. 2007; 22(10):1434-8.

24. Chen DCR, Kirshenbaum DS, Yan J, Kirshenbaum E, Aseltine RH. Characterizing changes in student empathy throughout medical school. Med Teach. 2012; 34(4):305-11. 
25. Hojat M, Mangione S, Nasca TJ, et al. An empirical study of decline in empathy in medical school. Med Educ. 2004; 38(9):934-41.

26. Hojat M, Vergare J, Maxwell K, et al. The devil is in the third year: a longitudinal study of erosion of empathy in medical school. Acad Med. 2009; 84(9):1182-91.

27. Hosseini MK, Hosseini ZK, Mahmoodian F. Comparison of empathy score among medical students in both basic and clinical levels. J Adv Med Educ and Prof. 2014; 2(2):88-91.

28. Neumann M, Edelhauser F, Tauschel D, et al. Empathy decline and its reasons: a systematic review of studies with medical students and residents. Acad Med. 2011; 86(8):996-1009.

29. Hojat M, Fields SK, Gonnella JS. (2003). Empathy: An NP/MD comparison. Nurse Practitioner. 2003; 28(4):45-47.

30. Sherman JJ, Cramer A. Measurement of changes in empathy during dental school. J Dent Educ. 2005; 69(3):338-45.

31. Ward J, Cody J, Schaal M, Hojat M. The empathy enigma: An empirical study of decline in empathy among undergraduate nursing students. J Prof Nurs. 2012; 28(1):34-40.

32. Wilson SE, Prescott J, Becket G. Empathy levels in first- and third-year students in health and non-health disciplines. Am J Pharm Educ. 2012; 76(2): Article 24. https://doi.org/10.5688/ajpe76224.

33. Hojat M, Shannon SC, DeSantis J, Speicher MR, Bragan L, Calabrese LH. Does empathy decline in the clinical phase of medical education? A nationwide, multi-institutional, cross-sectional study of students at DO-granting medical schools. Acad Med. 2020; 95(6):911-918.

34. Van Winkle LJ, Fjortoft N, Hojat M. Impact of a workshop about aging on the empathy scores of pharmacy and medical students. Am J Pharm Educ. 2012; 76(1):Article 9. https://doi.org/10.5688/ajpe7619.

35. Chen JD, LaLopa J, Dang DK. Impact of patient empathy modeling on student pharmacists caring for the underserved. Am J Pharm Educ. 2002; 72(2):Article 40.

36. Williams CR, Rodgers P, McLaughlin J, Angelo T, Shepherd G. Comparing Empathy Levels in Doctor of Pharmacy Students and Exemplary Pharmacist Preceptors. Am J Pharm Educ. 2020; 84(3):Article

7497; https://doi.org/10.5688/ajpe7497.

37. Kaiser, H.F. An index of factorial simplicity. Psychometrika. 1974; 39:31-36. https://doi.org/10.1007/BF02291575.

38. HF Kaiser, J Rice. Little Jiffy, Mark IV. Educ Psychol Meas. 1974; 34:111-117.

39. R Core Team. R: A language and environment for statistical computing. R Foundation for Statistical Computing, Vienna, Austria. 2021. https://www.R-project.org/. Accessed August 3, 2020.

40. Maier MJ (2015)._Companion Package to the Book "R: Einführung durch angewandte Statistik" . R package version 0.9.3. https://cran.r-project.org/web/packages/REdaS/REdaS.pdf. Accessed August 3, 2020.

41. Hector Corrada Bravo and Brian Borchers (2020). Rcsdp: R Interface to the CSDP Semidefinite Programming Library. R package version 0.1.57.1. https://CRAN.R-project.org/package=Rcsdp. Accessed August 3, 2020.

42. Yves Rosseel (2012). lavaan: An R Package for Structural Equation Modeling. Journal of Statistical Software, 48(2), 1-36. URL https://www.jstatsoft.org/v48/i02/. Accessed August 3, 2020.

43. Kim H. Statistical notes for clinical researchers: assessing normal distribution (2) using skewness and kurtosis. Restor Dent Endod. 2013; 38(1):52-54.

44. Shin HS, Park H, Lee Y. The relationship between medical students' empathy and burnout levels by gender and study years. Patient Educ Couns. 2021 May 29;S0738-3991(21)00391-8. doi: 10.1016/j.pec.2021.05.036. Online ahead of print.

45. Trauernicht M, Oppermann E, Klusmann U, Anders Y. Burnout undermines empathising: do induced burnout symptoms impair cognitive and affective empathy? Cogn Emot. 2021; 35(1):185-192.

46. Lamothe M, Boujut E, Zenasni F, Sultan S. To be or not to be empathic: the combined role of empathic concern and perspective taking in understanding burnout in general practice. BMC Fam Pract. 2014 Jan 23;15:15.

47. Walker PC, Kinsey KS, Kraft MD, Mason NA, Clark JS. IPPE: Improving student education and patient care through an innovative introductory pharmacy practice experience. Am J Health Syst Pharm. 2011; 68(8):655, 658, 660.

48. Walker PC, Kraft MD, Kinsey KS, van Kampen A, Perez M, Okeagu U, Boateng A. Making Student Pharmacists Indispensable: The Added Value of Introductory Pharmacy Practice Experience Students to Patient Care. Curr Pharm Teach Learn. 2015; 7(1): 47-53.

49. Hojat M, LaNoue M. Exploration and confirmation of the latent variable structure of the Jefferson scale of empathy. Inter J Med Educ. 2014; 5:73-81. 
Table 1. Student Characteristics and Jefferson Scale of Empathy-Health Profession Student Version (JSE-HPS) Mean Scores at Baseline

\begin{tabular}{lccc}
\hline & N=82 (\%) & $\begin{array}{c}\text { JSE-HPS Score } \\
\text { M (SD) }\end{array}$ & P-value \\
\hline All Students & & $111.5(10.5)$ & \\
Gender & $49(59.8 \%)$ & $110.7(10.9)$ & $.650^{\mathrm{a}}$ \\
$\quad$ Female & $30(36.6 \%)$ & $112.9(10.0)$ & \\
$\quad$ Male & $3(3.7 \%)$ & $112.7(12.6)$ & \\
$\quad$ Not specified & $16(19.5 \%)$ & $110.5(10.2)$ & $.364^{\mathrm{a}}$ \\
What is your age in years? & $51(62.2 \%)$ & $113.0(11.0)$ & \\
19-21 years & $7(8.5 \%)$ & $105.4(8.1)$ & $.380^{\mathrm{b}}$ \\
22-24 years & $5(6.1 \%)$ & $111.6(9.6)$ & \\
$25-27$ years & $3(3.7 \%)$ & $106.0(7.5)$ & $.245^{\mathrm{b}}$ \\
28-30 years & & & \\
$31-51$ years & $31(37.8 \%)$ & $110.112 .4)$ & \\
Have you worked in a pharmacy in the past? & $51(62.2 \%)$ & $112.4(9.3)$ & \\
$\quad$ No & & $114.9(11.1)$ & \\
$\quad$ Yes & $13(15.9 \%)$ & $110.9(10.4)$ & \\
Have you had any patient interactions in the past? & $69(84.1 \%)$ &
\end{tabular}

a one-way ANOVA

${ }^{b} t$-test for Independent Samples 


\begin{tabular}{|c|c|c|c|c|c|c|c|c|c|c|c|}
\hline \multirow[b]{2}{*}{ Time of Assessment } & \multirow{2}{*}{$\begin{array}{c}\text { All } \\
\text { Students } \\
(\mathrm{N})\end{array}$} & \multirow{2}{*}{$\begin{array}{l}\text { Male, } \\
(\mathrm{N})\end{array}$} & \multirow[b]{2}{*}{$\begin{array}{l}\text { Female, } \\
(\mathrm{N})\end{array}$} & \multicolumn{4}{|c|}{ JSE-HPS $^{\mathrm{b}}$} & \multirow[b]{2}{*}{ Range } & \multirow[b]{2}{*}{ Skewness } & \multirow[b]{2}{*}{ Kurtosis } & \multirow{2}{*}{$\begin{array}{c}\text { Greatest } \\
\text { Lower } \\
\text { Bound }\end{array}$} \\
\hline & & & & Mean $(\mathrm{SD})^{\mathrm{c}}$ & $\begin{array}{c}\text { Male } \\
\text { Mean (SD) }\end{array}$ & $\begin{array}{c}\text { Female } \\
\text { Mean (SD) }\end{array}$ & Median & & & & \\
\hline All Years & $334^{\mathrm{d}}$ & 123 & 200 & $111.3(13.0)$ & $113.5(12.0)$ & $109.7(13.5)$ & 112 & $73-137$ & -.53 & 3.34 & 0.93 \\
\hline $\begin{array}{l}\text { Beginning of Year - } \\
\text { PY1 (Baseline) }\end{array}$ & 82 & 30 & 49 & $111.5(10.5)$ & $112.9(10.0)$ & $110.7(10.9)$ & 112 & $88-136$ & -.05 & 2.26 & .92 \\
\hline End of Year - PY1 & 80 & 29 & 48 & $109.9(13.7)$ & $109.6(13.1)$ & $109.8(14.3)$ & 113 & $73-137$ & -.73 & 3.17 & .95 \\
\hline End of Year - PY2 & 75 & 27 & 46 & $107.6(15.1)$ & $112.0(12.5)$ & $104.8(15.9)$ & 108 & $76-134$ & -.23 & 2.36 & .97 \\
\hline End of Year - PY3 & 20 & 8 & 12 & $120.0(8.9)$ & $123.0(7.3)$ & $118.1(9.5)$ & 122.5 & $97-131$ & -.91 & 3.23 & 1.00 \\
\hline End of Year - PY4 & 77 & 29 & 45 & $113.8(12.2)$ & $116.9(11.8)$ & $111.4(12.1)$ & 114.5 & $74-136$ & -.46 & 3.34 & .96 \\
\hline
\end{tabular}

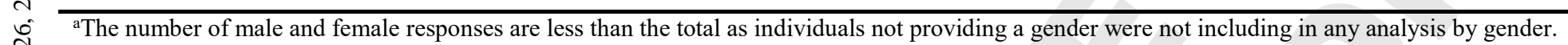

bJSE-HPS = Jefferson Scale of Empathy-Health Profession Student Version

'ANOVA F(4/329) 4.9; $\mathrm{P}=0.001$

dTotal number of observations for all students, 
Table 3. All-pairwise Regression Comparisons of Jefferson Scale of Empathy-Health Profession Student Version (JSE-HPS) Mean Scores by Year

\begin{tabular}{lccc}
\hline \multicolumn{1}{c}{ Years Compared } & $\begin{array}{c}\text { Difference } \\
\text { in Means }\end{array}$ & $\begin{array}{c}\text { Model Estimate }(95 \% \\
\text { Confidence Interval) }\end{array}$ & P-value \\
\hline Baseline to EOY PY1 & -1.65 & $-1.58(-4.85,1.70)$ & .677 \\
Baseline to EOY PY2 & -3.93 & $-3.51(-6.85,-0.17)$ & $.034^{*}$ \\
Baseline to EOY PY3 & 8.40 & $3.86(-1.63,9.34)$ & .303 \\
Baseline to EOY P4 & 2.24 & $2.32(-0.98,5.63)$ & .304 \\
EOY PY1 to EOY PY2 & -2.28 & $-1.93(-5.28,1.42)$ & .509 \\
EOY PY1 to EOY PY3 & 10.05 & $5.43(-0.05,10.92)$ & .054 \\
EOY PY1 to EOY P4 & 3.89 & $3.90(0.59,7.21)$ & $.012^{*}$ \\
EOY PY2 to EOY PY3 & 12.33 & $7.36(1.84,12.88)$ & $.003^{*}$ \\
EOU PY2 to EOY P4 & 6.17 & $5.83(2.46,9.20)$ & $<.001^{*}$ \\
EOY PY3 to EOY P4 & -6.16 & $-1.53(-7.04,3.97)$ & .940 \\
\hline
\end{tabular}

*Tukey HSD all-pairwise adjusted, significance at $\mathrm{P}=.05$ $\mathrm{EOY}=$ End of Year

PY1 = First Professional Year; PY2 = Second Professional Year; PY3 = Third Professional Year; P4 = Fourth Professional Year 